\title{
Accumulation of beneficial bacteria in the rhizosphere of maize (Zea mays L.) grown in a saline soil in responding to a consortium of plant growth promoting rhizobacteria
}

Jieli Peng ${ }^{1}$, Jia Ma ${ }^{1}$, Xiaoyan Wei ${ }^{1}$, Cuimian Zhang ${ }^{1}$, Nan Jia ${ }^{1}$, Xu Wang ${ }^{1}$, En Tao Wang ${ }^{2}$, Dong Hu ${ }^{1 *}$ (iD and Zhanwu Wang ${ }^{1 *}$

\begin{abstract}
Purpose: Salt stress reduces plant growth and is now becoming one of the most important factors restricting the agricultural productivity. Inoculation of plant growth-promoting rhizobacteria (PGPR) has been shown to confer plant tolerance against abiotic stress, but the detailed mechanisms of how this occurs remain unclear and the application effects in different reports are unstable. In order to obtain a favorite effect of PGPR inoculation and improve our knowledge about the related mechanism, we performed this study to analyze the mechanism of a PGPR consortium on improving the salt resistance of crops.

Methods: A region-specific (Saline land around Bohai Sea in China) PGPR consortium was selected that contains three strains (Pseudomonas sp. P8, Peribacillus sp. P10, and Streptomyces sp. X52) isolated from rhizosphere of Sonchus brachyotus DC. grown in a saline soil. By inoculation tests, their plant growth-promoting (PGP) traits and ability to improve the salt resistance of maize were investigated and shifting in rhizosphere bacterial community of the inoculated plants was analyzed using the high-throughput sequencing technology.

Results: The three selected strains were salt tolerant, presented several growth promoting properties, and inhibited several phytopathogenic fungi. The inoculation of this consortium promoted the growth of maize plant and enriched the beneficial bacteria in rhizosphere of maize in a saline soil, including the nitrogen fixing bacteria Azotobacter, Sinorhizobium, and Devosia, and the nitrification bacteria Candidatus Nitrososphaera, and Nitrosovibrio.

Conclusions: The bacterial consortium P8/P10/X52 could improve plant growth in a saline soil by both their PGP traits and regulating the rhizosphere bacterial community. The findings provided novel information about how the PGPR helped the plants in the view of microbiome.
\end{abstract}

Keywords: Consortium inoculant, Saline soil, Rhizobacteria, Plant promoting trait, Maize

\footnotetext{
* Correspondence: donghu1983@163.com; zhanwuw@126.com

${ }^{1}$ Institute of Agro-resources and Environment (Hebei Fertilizer Technology Innovation Center), Hebei Academy of Agriculture and Forestry Sciences, Shijiazhuang, Hebei, People's Republic of China

Full list of author information is available at the end of the article
}

(c) The Author(s). 2021 Open Access This article is licensed under a Creative Commons Attribution 4.0 International License, which permits use, sharing, adaptation, distribution and reproduction in any medium or format, as long as you give appropriate credit to the original author(s) and the source, provide a link to the Creative Commons licence, and indicate if changes were made. The images or other third party material in this article are included in the article's Creative Commons licence, unless indicated otherwise in a credit line to the material. If material is not included in the article's Creative Commons licence and your intended use is not permitted by statutory regulation or exceeds the permitted use, you will need to obtain permission directly from the copyright holder. To view a copy of this licence, visit http://creativecommons.org/licenses/by/4.0/ 


\section{Introduction}

Soil salinity is a common problem and one of the main abiotic stress factors that inhibit plant growth and development (Egamberdieva et al. 2019). Salinization refers to the concentration increase or accumulation of watersoluble salts in soil. Salt-affected soils are classified by electrical conductivity $\left(\mathrm{EC}>4 \mathrm{dS} \mathrm{m}^{-1}, \sim 0.3 \%\right)$, the exchangeable sodium percent (ESP $>6 \%$ ), or $\mathrm{pH}$ usually over 8.5 . The salts mainly caused by the flooding and seepage of seawater, rising of brackish groundwater in areas with low rainfall and high evaporation, or saline irrigation water and poor water management in agricultural areas (Ondrasek and Rengel 2021). As the most important type of soil degradation, soil salinization seriously affects crop production mainly by decreasing the osmotic potential of the soil that makes the plants difficult to absorb water, but also by the direct toxic of salts. With the human activity in arable land, such as excessive and long term supply of chemical fertilizers, the degree of secondary salinization of soil becomes more and more serious. Therefore, soil salinization forms a limitation to fit the increased food demand companied with the development of human society and the increase of population.

In general, around $953 \times 10^{6}$ ha or $20 \%$ of the irrigated areas of the world have been affected by salinization, and the salinity problem is more common in semi-arid regions, as reported in Brazil, India, and China, due to the low rainfall against high evaporative rate (Fagundes et al. 2020; Singh 2021). In China, there are about $36 \times$ $10^{6}$ ha of land with saline soil, accounting for about $5 \%$ of the total available land base of the country. Although these regions presented low agricultural productivity, the saline soils forms an important potential resource for arable land.

Attempts to improve the crop production in the saline lands have been made in China since 1930s ( $\mathrm{Li}$ et al. 2014). The related studies have been focused on two aspects: land management or technologies to promote the soil desalination; and breeding crop cultivars resistant or adapted to the saline soils. Some of the methods are also applied in other countries. Rice production in the Mekong River Delta of Vietnam (MRD) is endangered by sea-level rise and an associated increase in the incidence of salinity intrusion. Diffusion of salt tolerant rice varieties in the MRD has been performing to solve this problem (Paik et al. 2020). Some well-proven, widely used and cost-effective traditional ameliorative strategies (e.g., conservation agriculture, application of natural conditioners) helped the crops against salinity and other constraints, especially in developing countries (Ondrasek and Rengel 2021).

Some desalinization technologies have been developed in previous studies, such as the drainage-based cropping system, physical adsorption improvement, brine discharge pipe, slag adsorption etc., but all of them are fresh water consuming procedures that is not suitable for arid and semi-arid areas (Ilangumaran and Smith 2017). On the other hand, in order to improve the salt tolerance of plants, mechanisms (including genes) of the salt resistance in plants have been studied (Li et al. 2014; Ondrasek and Rengel 2021), including the use of plant growth-promoting rhizobacteria (PGPR), traditional breeding and genetic engineering (Fita et al. 2015; Yang et al. 2009). Traditional breeding and genetic engineering usually need a long period for obtaining progress or success, and PGPR can greatly improve the salt tolerance (Chen et al. 2016), drought resistance and growth of crops with low cost and short time. PGPR have been used in promoting plant growth and disease prevention that in turn could improve the productivity in saline land (Palaniyandi et al. 2014). Therefore, the application of PGPR is one of the most promising alternatives for improving plant growth in saline soil (Numan et al. 2018; Yang et al. 2009). At present, the use of PGPR to improve salt stress in crop production is becoming more and more common. Various salt-tolerant PGPR, including Azospirillum, Burkholderia, Rhizobium, Pseudomonas, Acetobacter and Bacillus associated with different plants have been successfully applied or tested for improving plant growth under salt stress (Chatterjee et al. 2017; Egamberdieva et al. 2015). Maize is one of the most important cereal crops that is mainly planted in irrigated agricultural areas in both arid and semi-arid regions (Nuss and Tanumihardjo 2010). As a moderately salinity-sensitive plant species, few salinity-tolerant maize cultivars have been commercialized, but PGPR can improve maize salt tolerance (Chen et al. 2016). However, these bacteria have not been fully investigated, especially in arid and semiarid regions, and their effects in application were not suitable and unstable in some cases, in addition to their limited application range (Wu et al. 2012). Furthermore, few of the microbial strains presented wide and strong adaptability in the soil.

Considering that the biogeographic patterns of the soil bacteria (Chu et al. 2020; Li et al. 2020) and plant associated bacteria (Román-Ponce et al. 2016; Zhang et al. 2011) are determined by the soil physiological and biological traits, we propose that region-specific PGPR might have a stable effect on improve the salt resistance of the local crops. In order to verify this hypothesis, we performed the present study by using a set of efficient bacteria screening methods for searching salt-tolerance PGPR against Sonchus brachyotus DC. (common name Qumacai or Kujucai in China) from rhizosphere of plants grown in a saline land in Haixing County, Hebei Province of China. A consortium composed of three strains was selected based upon their salt resistance and 
PGP traits, and its effects on maize growth and rhizosphere microbiota were investigated. The results provided theoretical support for application of the PGPR consortium in improving the productivity in saline land and in sustainable agriculture.

\section{Materials and methods}

\section{Bacterial isolation}

Rhizobacteria were isolated from Sonchus brachyotus rhizosphere soil collected in saline field in Haixing County, Cangzhou City, Hebei Province of China. A rhizosphere soil suspension was obtained by shaking off and discarded the loosely soil then rinsing the roots with adhered soil in phosphate-buffered for $10 \mathrm{~min}$ at 150 $\mathrm{rpm}$. The suspension was serially diluted to $10^{-6}$, and aliquots of $0.1 \mathrm{~mL}$ of the last three dilutions were spread separately onto $1 / 3$ King'B medium (KMB, 6.5 g Peptone, $0.5 \mathrm{~g} \mathrm{~K}_{2} \mathrm{HPO}_{4}, 0.5 \mathrm{~g} \mathrm{MgSO}_{4} .7 \mathrm{H}_{2} \mathrm{O}, 3 \mathrm{~mL}$ Glycerol, $18 \mathrm{~g}$ agar, add $\mathrm{dH}_{2} \mathrm{O}$ to $1 \mathrm{~L}$ ) and incubated at $30{ }^{\circ} \mathrm{C}$ for 48 h. Single colonies with different morphology traits (shape, color, size, luster, texture, light transparence, edge integrity) were picked up and re-streaked several times on the same medium to obtain the pure culture. The purified bacteria were maintained at slants of $1 / 3$ $\mathrm{KMB}$ medium at $4{ }^{\circ} \mathrm{C}$ for short time storage (3-4 weeks) or in broth of the same medium supplied with $30 \%$ (w/ v) glycerol at $-80^{\circ} \mathrm{C}$ for long-term storage.

\section{Selection of the PGPR and estimation of their PGP traits} The salt resistance of the isolates was tested by grown them on $1 / 3$ King'B medium supplied with $0 \%, 5 \%$, and $10 \%(\mathrm{w} / \mathrm{v})$ of $\mathrm{NaCl}$. The growth promoting properties of the isolates were tested according the reported methods. Briefly, the production of IAA (indole-3-acetic acid) was determined by the method of Khalid et al. 2004 and Bric et al. 1991; the production of ACCD (1-aminocyclopropane-1-carboxylic acid deaminase) was determined by the method of Penrose and Glick 2003]; the production of siderophores was estimated based on the work of Schwyn and Neilands 1987; phosphate solubilization potential was determined by the method of Vyas et al. 2007; and nitrogen fixation capacity was investigated using the method of Dobereiner et al. 1976. All the tests were performed in triplicate by incubation at $30{ }^{\circ} \mathrm{C}$ for 48-96 h. IAA production and ACCD activities were also quantitatively determined with the methods described previously (Khalid et al. 2004; Penrose and Glick 2003). Based upon their salt tolerance and PGP traits, isolates with strong ACCD activity, high nitrogen fixation ability, high phosphate solubilization, and high IAA and siderophore production were selected to compose a consortium as PGPR inoculant. In addition, these isolates with different colony morphologies without nutritional competition were also considered as the selection criteria.

All the selected isolates were tested for their in vitro inhibition against the phytopathogenic fungi Pythium aphanidermatum MJ-1, Fusarium oxysporium f.sp. cucumerinum HG-11, Curvularia lunata sp. WM-1, Cochliobolus heterostrophus sp. WM-2, and Phytophthora capsici LJ-3 on $1 / 3$ King'B medium by plate confrontation method and plate diffusion method according to the references (Fernandez-Garayzabal et al. 1992). Diameter in $\mathrm{mm}$ of the fungal colonies in both the control (without bacterial inoculant) and the test (co-incubated with bacteria) was measured after 7 days incubation at $28{ }^{\circ} \mathrm{C}$. The inhibition (\%) was presented as $100 \times$ (radius of control colony -radius of colony in test)/radius of control colony. All the tests were performed in triplicate.

\section{Bacterial identification}

For identification of the selected isolates, bacterial genomic DNA was extracted by the $\mathrm{CTAB} / \mathrm{NaCl}$ method (Andreou 2013) from $5 \mathrm{~mL}$ of culture in broth of $1 / 3$ King'B medium incubated at $30{ }^{\circ} \mathrm{C}$ for $24 \mathrm{~h}$ with agitation, and the almost complete $16 \mathrm{~S}$ rDNA was amplified from the DNA extract by using PCR with the universal bacterial primers $27 \mathrm{~F}$ and 1492R (Frank et al. 2008). The PCR product was sequenced commercially in Invitrogen (Shanghai) with the same primers and the acquired sequences were analyzed with BLASTn to identify the isolates at genus/species level.

\section{Plant growth conditions and treatments}

The saline soil used for the pot experiment was obtained from 0 to $30 \mathrm{~cm}$ in depth at the Haixing Farm $(38.04 \mathrm{~N}$ 117.24 E) that located in the same region for the bacterial isolation. The soil was air-dried and sieved to $2.5 \mathrm{~mm}$ before filling in the pot. The basic physicochemical properties of the soil were $\mathrm{pH} 8.39$, total salt $3.09 \%$, organic matter $4.45 \mathrm{~g} \mathrm{~kg}^{-1}$, total $\mathrm{N}$ (TN) $0.27 \mathrm{~g} \mathrm{~kg}^{-1}$, alkalihydrolyzable N $22.75 \mathrm{mg} \mathrm{kg}^{-1}$, total phosphorus (P) 0.69 $\mathrm{g} \mathrm{kg}^{-1}$, available $\mathrm{P}$ (AP) $10.39 \mathrm{mg} \mathrm{kg}$, total potassium (K) $18.59 \mathrm{~g} \mathrm{~kg}^{-1}$ and available $\mathrm{K}$ (AK) $101.75 \mathrm{mg} \mathrm{kg}^{-1}$. The non-saline soil obtained from Experimental Farm (38.05 N 114.44 E) in Shijiazhuang City, Hebei Province, was also used for a parallel experiment, which presented the basic physicochemical properties as following: $\mathrm{pH}$ 7.27 , total salt $0.09 \%$, organic matter $18.18 \mathrm{~g} \mathrm{~kg}^{-1}$, total $\mathrm{N}$ (TN) $1.07 \mathrm{~g} \mathrm{~kg}^{-1}$, alkalihydrolyzable $\mathrm{N} 68.60 \mathrm{mg} \mathrm{kg}$, total phosphorus (P) $0.90 \mathrm{~g} \mathrm{~kg}^{-1}$, available P (AP) 27.19 mg kg-1 total potassium (K) $19.46 \mathrm{~g} \mathrm{~kg}^{-1}$ and available $\mathrm{K}$ (AK) $150.00 \mathrm{mg} \mathrm{kg}$. For the subsequent analysis, a 
mixture of the two soils $(1 \mathrm{~g}$ of the saline soil $+9 \mathrm{~g}$ of the non-saline soil) was prepared to get a soil with $0.31 \%$ of total salt, which is the limit concentration for surviving of maize in a preliminary test.

To define whether the bacteria had an effect on the growth of maize in saline condition, surface-sterilized and synchronized seeds of cultivar Zhengdan 958 were incubated with bacterial suspension $\left(10^{6} \mathrm{CFU} / \mathrm{mL}\right)$ prepared by mixing the three selected isolates P8, P10, and X52 in the same ratio (1:1:1 in volume) or sterilized water solution as a control for $12 \mathrm{~h}$ and then pregerminated on sand under $0.0 \%$ and $0.3 \% \mathrm{NaCl}$ concentrations and on the mixed soil containing $0.3 \%$ total salt. The germinated seeds were sown in pots filled with the natural soil samples (200 g soil in each 1 litter pot, one seed per pot). Potted plants were placed in a growth chamber at $25{ }^{\circ} \mathrm{C}$ with a $16 / 8 \mathrm{~h}$ light/dark cycle. Deionized water was supplied from the bottom of the pot. Finally, 25 days after sowing, plant agronomic traits were determined, including shoot length, root length, shoot dry weight, and root dry weight. Each treatment has three replicates $(n=3)$.

\section{Rhizosphere bacterial community analysis by $16 \mathrm{~S}$ rDNA gene sequencing}

To investigate the effect of $\mathrm{P} 8 / \mathrm{P} 10 / \mathrm{X} 52$ consortium on maize rhizosphere microbiota in saline soil, sterilized and synchronized seeds were inoculated by immerging the seeds with the consortium suspension $\left(1: 1: 1,10^{5}\right.$ $\mathrm{CFU} / \mathrm{mL} / \mathrm{strain}$ ) or with sterilized water solution as a control for $12 \mathrm{~h}$ and then pregerminated on the mixed soil containing $0.31 \%$ of total salt. Pregerminated seeds were sown in a stone pot with dimensions of $305 \mathrm{~mm}$ (height) $\times 225 \mathrm{~mm}$ (open top) $\times 205 \mathrm{~mm}$ (flat bottom) which were filled with $7 \mathrm{~kg}$ of the mixed soil samples supplied with inorganic fertilizers $\left(\mathrm{kg} \mathrm{ha}^{-1}\right)$ in the ratio of $150 \mathrm{~N}, 75 \mathrm{P}_{2} \mathrm{O}_{5}$ and $75 \mathrm{~K}_{2} \mathrm{O}$. Each treatment had 48 replicate pots. The growth conditions were the same as described above and supplied each pots in equal watering every 15 days. The rhizosphere soil was sampled at the three-leaf stage (10 days after sowing), jointing stage (27 days after sowing), tasseling stage (52 days after sowing), and maturity stage (100 days after sowing) in three replicates for analyzing the microbiota by the high throughput DNA sequencing described subsequently.

The rhizosphere soil samples were obtained according to previous research (Hu et al. 2020). In brief, they were sampled by brushing off the soils attached to the root surface with a soft toothbrush. Samples from the three plants (repeats) were compiled to form a composite sample and were stored at $-80{ }^{\circ} \mathrm{C}$ until it was used for DNA extraction.

The metagenomic DNA was extracted from $0.5 \mathrm{~g}$ rhizosphere soil and purified by using PowerSoil DNA Isolation Kit (Mo Bio Laboratories Inc., Carlsbad, CA,
USA) according to the manufacturer's instructions. The quality and quantity of the extracts were measured by the Nano Drop ${ }^{\mathrm{Ta}} 2000$ spectrophotometer (Nano Drop Technologies, Wilmington, DE, USA). Primer set of F515 (5'-GTGCCAGCMGCCGCGG-3') and R907 (5'CCGTCAATTCMTTTRAGTTT-3') was used to amplify the V4-V5 hypervariable regions of bacterial $16 \mathrm{~S}$ rRNA gene by PCR (Zhou et al. 2011). PCR products were purified and sequenced on a single lane of Illumina MiSeq platform at the Shanghai Personal biotechnology Co., Ltd (Personalbio, Shanghai, China).

Sequencing libraries were generated using the Illumina Nano DNA LT Library Prep KitTruSeq DNA PCR-Free Library Preparation Kit (Illumina, San Diego, USA) by following the manufacturer's recommendations. Library quality was assessed on a Qubit@ 2.0 Fluorometer (Thermo Fisher Scientific, Waltham, USA) and an Agilent Bioanalyzer 2100 system (Agilent Technologies, Santa Clara, USA). Finally, the library was sequenced on an Illumina MiSeq platform and 300 bp paired-end reads were generated (Personalbio, Shanghai, China). Raw reads were filtered by QIIME (Quantitative Insights Into Microbial Ecology) quality filters (Bokulich et al. 2013). The remaining reads from the original DNA fragments were merged using the FLASH tool (Magoč and Salzberg 2011). Paired-end reads were assigned to each sample according to unique barcodes with QIIME (Edgar 2010). OTUs (operational taxonomic units) with identities of $97 \%$ were determined for the quality filtrated reads using the Mothur software (http:// www. mothur.org), from which the Shannon diversity index and Chaol richness were estimated (White et al. 2009). The sequence with the highest relative abundance from each OTU was selected as the representative sequence to search the similar sequences in the National Center for Biotechnology Information (NCBI) nucleotide nonredundant database. PLS-DA (Partial least squares discriminant analysis) was also introduced as a supervised model to reveal the microbiota variation among groups, using the "plsda" function in R package "mixOmics" (Chen et al. 2011). Each group represents by one color and has three dots, which represent three repetitions and are marked with an ellipse. It would be better if the same color dots are closer, and the different color dots are farther.

Abundances of taxa at the genus levels were statistically compared among samples or groups by Metastats (http://metastats.cbcb.umd.edu/) (White et al. 2009). The difference in quantity (relatively abundance) of the OTUs was tested by pairwise comparison. Each time Metastats compares generated the corresponding $P$ and $Q$ values. The corrected $P$ value is called $Q$ value, and when $P$ value $<0.05$, the closer the $Q$ value is to 0 , the lower the probability of false positive. 


\section{Results}

\section{Selection of PGPR consortium}

Based on the PGP traits (Table 1), three isolates P8, P10, and X52 were able to grow in the presence of $5 \%$ and $10 \%(\mathrm{w} / \mathrm{v}) \mathrm{NaCl}$ were selected for constructing the consortium. Isolate P8 showed the best $\mathrm{N}$ fixation ability and the highest ACCD activity; P10 presented the best phosphate solubilization and $\mathrm{N}$ fixation ability, while X52 produced the highest IAA production and considerable siderophore production (Table 1). The quantitative analyses of IAA and ACCD revealed that X52 produced IAA as high as $70.58 \mu \mathrm{g} \mathrm{mL} \mathrm{m}^{-1}$, and $\mathrm{P} 8$ reached the ACCD activity of $8.01 \mathrm{mM} \mathrm{mg}^{-1} \mathrm{~h}^{-1}$ (Table 1 ).

Inhibition to phytopathogenic fungi by P8, P10, and X52 The antimicrobial activities of the selected isolates were summarized in Table 1 (details available as Suppl. Table S1). All the three isolates presented a certain degree of inhibition on all the tested fungal strains, in which the isolate X52 had the strongest inhibitory effects on four of the five pathogens (except F. oxysporium f. sp. cucumerinum HG-11), with the inhibition rates from $43.00 \%$ for $F$. oxysporium f.sp. cucumerinum HG-11 to $82.98 \%$ for B. maydis. For Fusarium, the highest inhibition (69.50\%) was found in culture with isolate P10. The broad antifungal spectrum presented in the three selected bacterial isolates, especially X52, evidenced them the potential for biological control application.

\section{Molecular identification of the selected bacteria}

The acquired 16S rDNA sequences of isolates P8, P10, and X52 were approximately $1.5 \mathrm{~kb}$ in length, which have been deposited in GenBank database under the accession numbers MT879460, MT878549, and MT878548, respectively. The BLAST search of these sequences against the GenBank database demonstrated that P8, P10 and X52 shared more than 99.7\% of sequence identity with reference strains for Pseudomonas silesiensis, Peribacillus simplex, and Streptomyces microflavus, respectively (Table 1). Therefore, the three isolates were identified as Pseudomonas sp. P8, Peribacillus sp. P10, and Streptomyces sp. X52.

\section{Enhancing maize salt stress tolerance by inoculation of P8/P10/X52 consortium}

As shown in Fig. 1, the maize seedlings grew similarly in the sand substrate with 0 and $0.3 \% \mathrm{NaCl}$ concentrations, and no significant difference was observed among different treatments in all the four growth traits: shoot length, root length, shoot dry weight, and root dry weight. So, maize growth was not affected by the salinity of $0.3 \%$ of $\mathrm{NaCl}$. However, the growth of maize seedlings was significantly improved by inoculation of the mixture of P8, $\mathrm{P} 10$, and $\mathrm{X} 52$ in sand despite the tested level of $\mathrm{NaCl}$, on the 25th day after sowing, comparing with the control group $(P<0.05)$ (Fig. 1$)$. These results implied that the consortium could improve the maize growth under

Table 1 Plant growth promoting traits and molecular identification of the selected strains in the consortium

\begin{tabular}{|c|c|c|c|c|}
\hline \multicolumn{2}{|l|}{ Tested trait } & Pseudomonas sp. P8 & Peribacillus sp. P10 & Streptomyces sp. X52 \\
\hline \multicolumn{2}{|l|}{ Morphological traits } & Round, yellow, opaque & Smooth, bulging, slimy, white & Dry, yellow, embed in the culture medium \\
\hline \multicolumn{2}{|l|}{ Phosphate solubilization } & $3^{\mathrm{a}}$ & 5 & 0 \\
\hline \multicolumn{2}{|l|}{ Nitrogen fixation } & 5 & 5 & 0 \\
\hline \multicolumn{2}{|l|}{ IAA production $\left(\mu \mathrm{g} \mathrm{mL}^{-1}\right)$} & $1(21.87)^{\mathrm{b}}$ & $1(11.25)$ & $5(70.58)$ \\
\hline \multicolumn{2}{|l|}{ ACCD activity ( $\left.m M \mathrm{mg}^{-1} \mathrm{~h}^{-1}\right)$} & $5(8.01)$ & $3(7.27)$ & $3(4.58)$ \\
\hline \multicolumn{2}{|l|}{ Siderophore production } & 2 & 2 & 3 \\
\hline \multirow[t]{2}{*}{ Growth at } & $5 \%(\mathrm{w} / \mathrm{v}) \mathrm{NaCl}$ & + & + & + \\
\hline & $10 \%(\mathrm{w} / \mathrm{v}) \mathrm{NaCl}$ & + & + & + \\
\hline \multirow[t]{5}{*}{ Growth Inhibition (IR\%) to } & Pythium sp. & 41.24 & 35.74 & 68.04 \\
\hline & Fusarium sp. & 23.00 & 69.50 & 43.00 \\
\hline & Curvularia lunata & 56.60 & 54.51 & 78.13 \\
\hline & Bipolaria maydis & 51.06 & 60.49 & 82.98 \\
\hline & Phytophthora sp. & 54.69 & 47.92 & 62.24 \\
\hline \multicolumn{2}{|l|}{ Most related species } & Pseudomonas silesiensis & Peribacillus simplex & Streptomyces microflavus \\
\hline \multicolumn{2}{|l|}{ Reference strain } & A3 & NBRC 15720 & 126182 \\
\hline \multicolumn{2}{|l|}{ Accession no. of $16 \mathrm{~S}$ rDNA } & NR156815 & NR115603 & JN180196 \\
\hline \multicolumn{2}{|l|}{ Identity of 165 rRNA gene } & $99.73 \%$ & $99.87 \%$ & $99.85 \%$ \\
\hline
\end{tabular}

IR inhibition rates of mycelium growth, IR(\%) (CR-TR/CR) $\times 100$

${ }^{a}$ The scores are estimated from the qualitative analysis, $0=$ negative; $5=$ the best

${ }^{\mathrm{b}}$ Results of quantitative analysis

${ }^{+}$Growth positive 


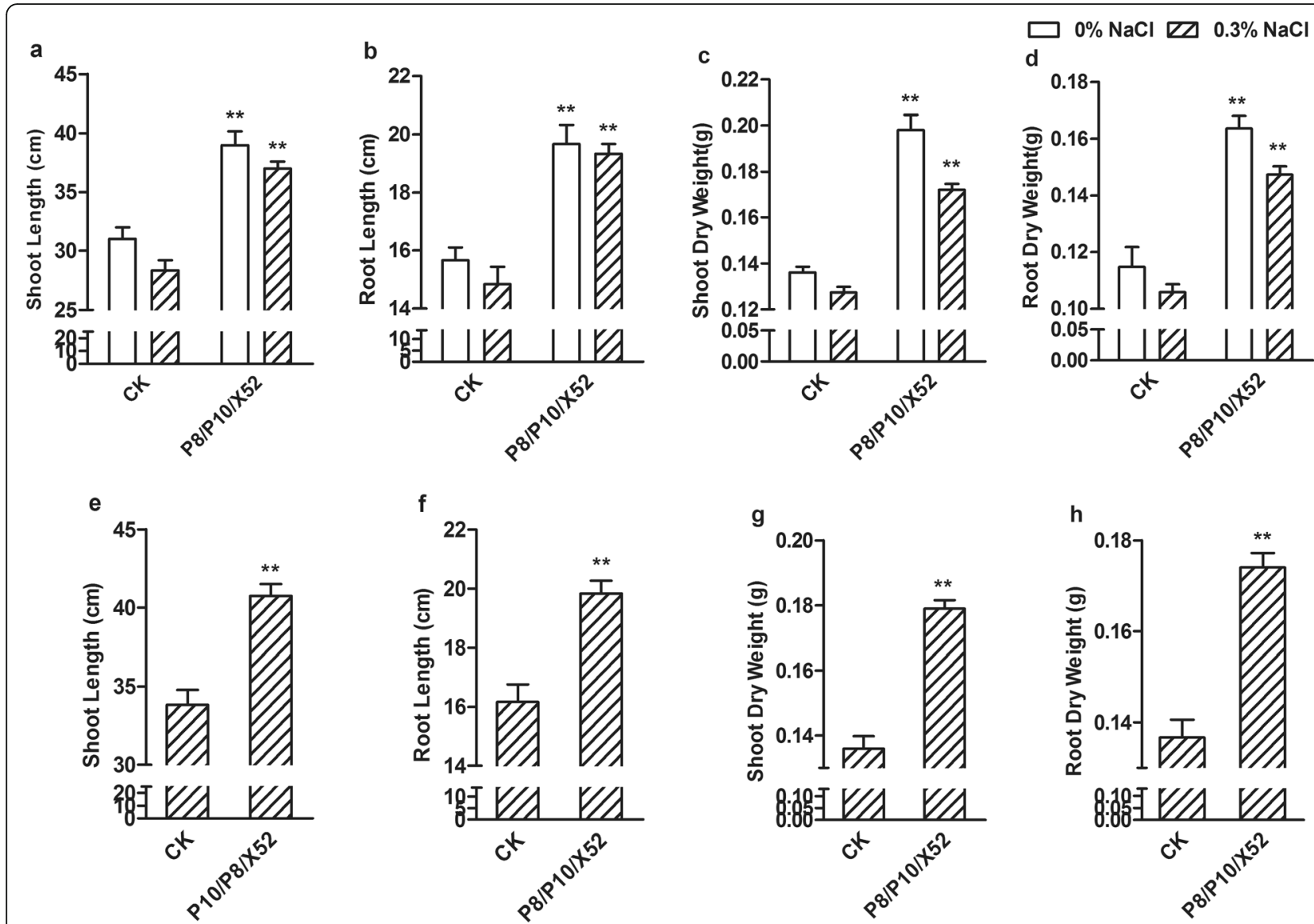

Fig. 1 The effects of P8/P10/X52 consortium on maize growth in substrates supplied with $0.3 \% \mathrm{NaCl}$. In sand: $\mathbf{a}$ the shoot length of maize; $\mathbf{b}$ the root length of maize; $\mathbf{c}$ the shoot dry weight; $\mathbf{d}$ the root dry weight of maize. In soil: $\mathbf{e}$ the shoot length of maize; $\mathbf{f}$ the root length of maize; $\mathbf{g}$ the shoot dry weight; $\mathbf{h}$ the root dry weight of maize. CK, control. ${ }^{* *}$ indicates the significant difference $(p<0.01)$ for treatments inoculated with P10/P8/X52 consortium compared with control (CK)

low level of saline stress $(0.3 \% \mathrm{NaCl})$. The effects of $\mathrm{P} 8 /$ P10/X52 consortium on maize growth were also verified in saline soil $(0.3 \% \mathrm{NaCl})$ (Fig. 1), by analysis of the same growth traits on the 25th day after sowing $(P<0.01)$ (Fig. 1). These results suggest that P8/P10/X52 consortium could promote the maize growth with or without slight salt stress.

\section{Promotion of the beneficial bacteria in maize rhizosphere} by consortium inoculation

Compared with the treatment of $\mathrm{P} 8 / \mathrm{P} 10 / \mathrm{X} 52$ consortium, germination time of control seeds is 1 day later and the plants grew with more pests and diseases in the mixed $0.3 \%$ saline soil. The plant growth and root development in control were also the worst, and the lower leaves became yellowish at the tasseling period. Finally, the maize yield of the P8/P10/X52 inoculation treatment increased by $16.52 \%(\mathrm{P}<0.05)$ compared to that of the control.

In the metagenomic analysis, a total of 626,785 highquality reads for the V4-V5 region of the 16S rRNA genes were obtained from the samples, with an average of 286,683 and 281,592 reads per sample of treatments and controls, respectively. These reads were rarefied to 6909 bacterial genes of each sample, corresponding to a total of 233,637 OTUs. The raw data have been deposited in SRA database under the accession numbers PRJNA562815. The OTU Shannon rarefaction curve (see Supplementary Fig. S1) tended to be flat and the Simpson index (see Supplementary Table S2) for most of the samples were greater than 0.90 (ranging from 0.76 to 0.99), suggesting that the sequencing depth of the samples can reflect the species diversity in the samples. The analysis of OTUs revealed differences in microbial community structure in rhizosphere of different growth stages and between control and P8/P10/X52 consortium inoculation (Fig. 2). The number of OTUs in the soil at the time of planting was the least; as the maize grew, the number of OTUs in the rhizosphere was increased; meanwhile, the bacterial abundance of treatment inoculated with P8/P10/X52 consortium was lower than that of control. 


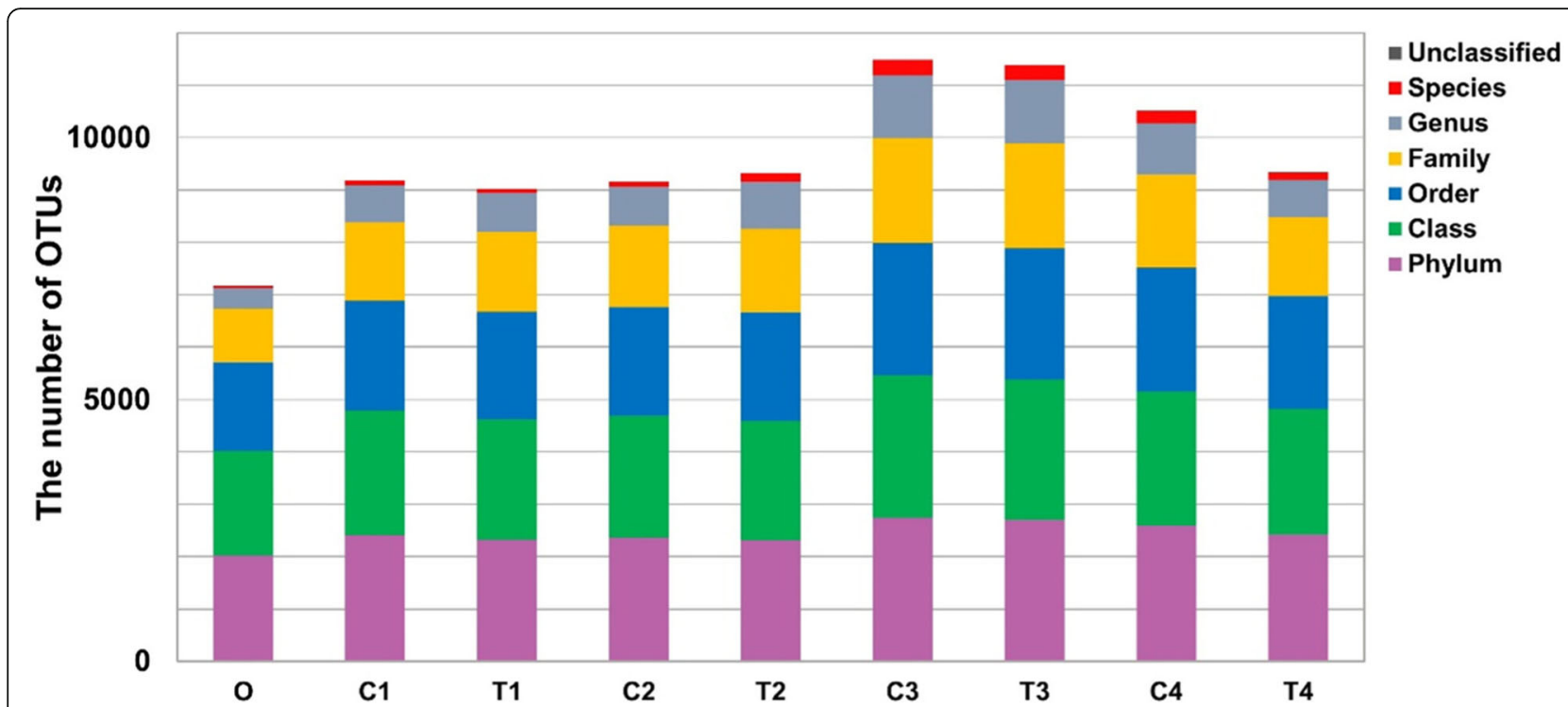

Fig. 2 The number of OTUs of soil in maize rhizosphere in different periods. Note: $\mathrm{O}$ indicate that the soil at the time of planting; $\mathrm{C} 1$ indicate that the rhizosphere soil at the time of the three-leaf stage of control; $C 2$ indicate that the rhizosphere soil at the time of the jointing stage of control; $\mathrm{C} 3$ indicate that the rhizosphere soil at the time of the tasseling stage of control; C4 indicate that the rhizosphere soil at the time of the maturity stage of control; $\mathrm{T} 1$ indicate that the rhizosphere soil at the time of the three-leaf stage of P8/P10/X52; T2 indicate that the rhizosphere soil at the time of the jointing stage of P8/P10/X52; T3 indicate that the rhizosphere soil at the time of the tasseling stage of P8/P10/X52; T4 indicate that the rhizosphere soil at the time of the maturity stage of P8/P10/X52

According to the PLS-DA (Fig. 3), the largest species diversity varied along the growth of maize plant. As maize grew, the difference in diversity between the P8/ P10/X52 inoculated treatments and the controls increased, and at the final maturity stage, the difference between the P8/P10/X52 treatments and the controls was the largest, suggesting that the microbial community composition in rhizosphere of maize was always changed related to the P8/P10/X52 inoculation.

The rhizosphere microbiota of maize varied among the four sampling stages, and the bacterial genera with significantly abundance were different according to the treatments and the growth stages of maize (Table 2). Some genera were more abundant in controls, but others were more abundant in P8/P10/X52 treatments, while several genera only existed in controls or in P8/ P10/X52 treatments. For instance, Exiguobacterium was only found in control at the three-leaf stage, and Cupriavidus only found in controls and Saccharopolyspora only recorded in P8/P10/X52 treatments at the jointing stage. At the maturity stage, the significantly different genera were the highest, and all of them presented higher abundances in P8/P10/X52 treatment. It's worth noting that most of the genera with significant difference in abundance at the maturity stage were related to the biological nitrogen fixation (such as Azotobacter, Sinorhizobium, and Devosia) and to nitrification (such as Candidatus Nitrososphaera, Nitrosovibrio), which are beneficial for restoring the soil ecology. These results suggest that inoculation of P8/P10/X52 consortium can enrich the rhizosphere microbiota and may promote the beneficial bacteria in the rhizosphere of maize grown in saline soil.

\section{Discussion}

The use of PGPR in agriculture as a sustainable and ecofriendly approach is a recommended strategy and an emerging trend in agriculture, including in saline soil (Numan et al. 2018; Yang et al. 2009). In the previous studies, salt-tolerant PGPR with various PGP traits have been tested (Chatterjee et al. 2017; Egamberdieva et al. 2015; Numan et al. 2018; Yang et al. 2009). However, most of the related studies used single strain as inoculant (Chatterjee et al. 2017; Egamberdieva et al. 2015), and the inoculation effects were unstable in some cases (Wu et al. 2012). For getting PGPR inoculant efficiently improving the growth and yield of staple crops in saline land, we tried in the present study to use consortium of PGPR as inoculant by combining strains with complementary PGP traits and without nutrient competition, and the results were encouraging.

In the present study, a set of efficient bacteria screening methods was employed for searching salt-tolerance PGPR from the rhizosphere of herbal plant Sonchus brachyotus grown in saline soil. Three strains of Pseudomonas sp. P8, Peribacillus sp. P10, and Streptomyces sp. X52 were selected based upon their salt tolerance and several growth promoting properties, as well as inhibiting several common pathogenic fungi (Table 1). The 


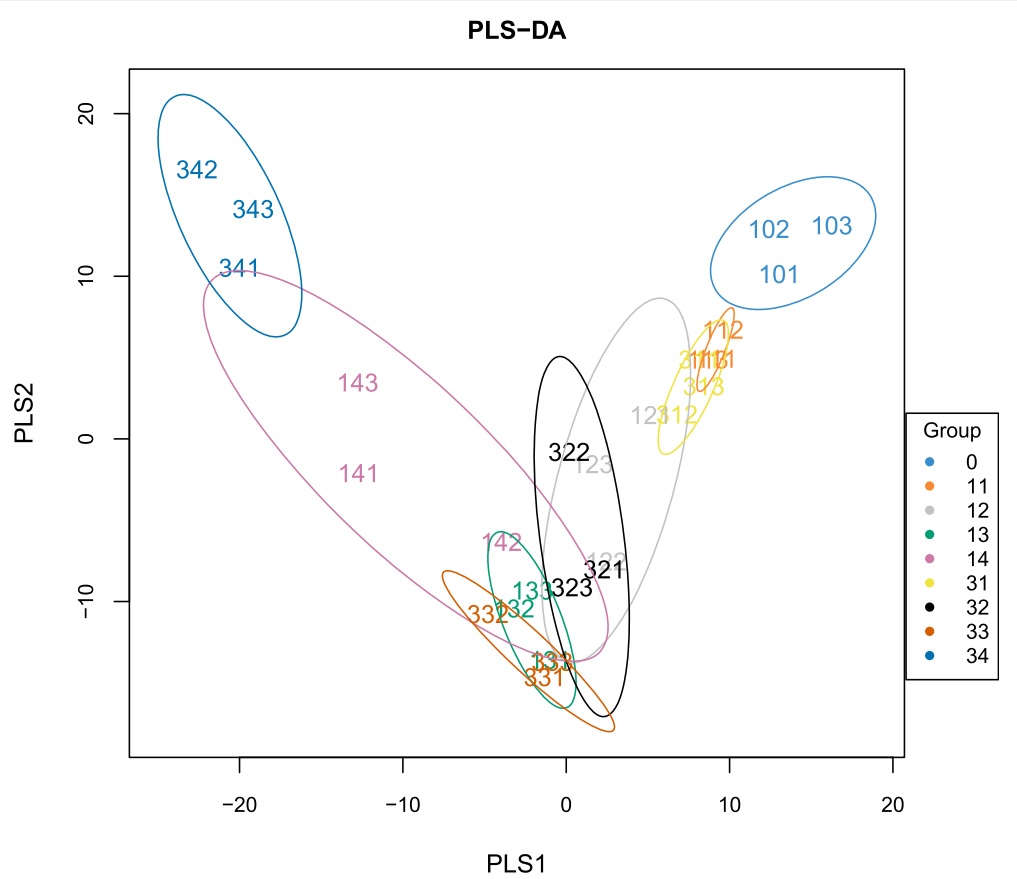

Fig. 3 Characteristics of soil colony in rhizosphere of maize in different growth stages. Samples marked with three numbers: 101, 102,103= repeats of soil at the time of planting; $111,112,113=$ rhizosphere soil at the three-leaf stage of control; $121,122,123=$ rhizosphere soil at the jointing stage of control; 131, 132, $133=$ rhizosphere soil at the tasseling stage of control; 141, 142, 143 = rhizosphere soil at the maturity stage of control; 311, 312, $313=$ rhizosphere soil at the three-leaf stage of inoculation (P8/P10/X52) treatment; 321, 322, $323=$ rhizosphere soil at the jointing stage of inoculation treatment; 331, 332, 333 = rhizosphere soil at the tasseling stage of inoculation treatment; $341,342,343=$ rhizosphere soil at the maturity stage of inoculation treatment

inoculation of consortium composed of these three strains could promote the seed germination and growth of maize plant in saline soil (Fig. 1). Previously, Pseudomonas and Bacillus strains, as well as Azospirillum, Burkholderia, Rhizobium, Acetobacter, and Raoultella planticola, have been used individually as PGPR to improve growth of various plants grown in saline soils, like red pepper and cotton plants, (Chatterjee et al. 2017; Egamberdieva et al. 2015; Wu et al. 2012). Among the three strains we selected, P10 belonged to the genus Peribacillus that was proposed recently as a new genus separated from Bacillus (Patel and Gupta 2020), while Streptomyces strains were also reported as PGP bacteria for different crops, like wheat grown in saline soil (Akbari et al. 2020; Olanrewaju and Babalola 2019). So, the isolation and identification of the three strains in the present study further revealed that Pseudomonas, Peribacillus, and Streptomyces are common PGPR in saline soils. Although the sequence identity (99.73\% to $99.87 \%$ ) of 16S rRNA gene between these three strains and the closely related reference strain for defined species were apparently greater than the suggested species threshold (97\%) (Gevers et al. 2005), we did not affiliate them into species, since the phylogeny of 16S rRNA gene is not sensitive enough for species definition in many cases.
The mechanisms for the PGP effects of PGPR have been reported and reviewed (Numan et al. 2018) previously, which can be sorted into two aspects: (1) PGPR stimulate the metabolic pathways of plants, such as stimulating plant synthesis of growth hormones, triggering the antioxidant system and starting siderophore production of plants, as well as augmenting nutritional capacity of the plants. (2) The PGPR themselves produce various phytohormones like auxins and cytokinins to improve the growth of both roots and shoots, or improve nutrient supplement by phytopathogenic antagonism, mineral solubilization, and nitrogen-fixation. In the present study, the three selected strains presented some of the PGP traits (Table 1), which might be a part of their mechanism to help the maize plant in alleviating stresses of salinity as reported previously (Etesami and Maheshwari 2018). Furthermore, these three strains were originately isolated from Sonchus brachyotus, but the consortium formed by them showed significant PGP effects on maize grown in the same soil; therefore, their host specificity is not strong, and they may also be used for other crops.

Except directly stimulating the plant growth, inoculation of the consortium in our study also regulated the microorganisms in the rhizosphere of maize: decreased 
Table 2 The difference in quantity (relatively abundance) of the rhizosphere microbiota of maize at each stage

\begin{tabular}{|c|c|c|c|c|c|}
\hline Period & Taxa of Genus & $\begin{array}{l}\text { Quantity } \\
\text { (Control) }\end{array}$ & $\begin{array}{c}\text { Quantity } \\
\text { (P8/P10/X52) }\end{array}$ & $p$-value & q-value \\
\hline \multirow[t]{13}{*}{ The three-leaf stage } & Lutibacterium & 0.000062 & 0.000419 & 0.000583 & 0.351104 \\
\hline & Rubrivivax & 0.000351 & 0.000171 & 0.006143 & 1.000000 \\
\hline & Actinomadura & 0.001119 & 0.000478 & 0.009750 & 1.000000 \\
\hline & Paucibacter & 0.000726 & 0.000171 & 0.010958 & 1.000000 \\
\hline & Exiguobacterium & 0.000189 & 0.000000 & 0.011577 & 1.000000 \\
\hline & Prauseria & 0.000194 & 0.000524 & 0.013423 & 1.000000 \\
\hline & Azotobacter & 0.028017 & 0.079611 & 0.016381 & 1.000000 \\
\hline & Lysobacter & 0.050258 & 0.158373 & 0.021220 & 1.000000 \\
\hline & Gemmatimonas & 0.000390 & 0.000104 & 0.021839 & 1.000000 \\
\hline & Ochrobactrum & 0.008147 & 0.004468 & 0.030970 & 1.000000 \\
\hline & Sediminibacterium & 0.002164 & 0.001447 & 0.038595 & 1.000000 \\
\hline & Pseudomonas & 0.505416 & 0.352078 & 0.042167 & 1.000000 \\
\hline & Streptomyces & 0.004631 & 0.003526 & 0.048940 & 1.000000 \\
\hline \multirow[t]{9}{*}{ The jointing stage } & Bacillus & 0.080522 & 0.267787 & 0.009631 & 1.000000 \\
\hline & Cellvibrio & 0.016103 & 0.005391 & 0.011142 & 1.000000 \\
\hline & Cupriavidus & 0.000384 & 0.000000 & 0.017255 & 1.000000 \\
\hline & Polaromonas & 0.001358 & 0.000198 & 0.023184 & 1.000000 \\
\hline & Saccharopolyspora & 0.000000 & 0.000404 & 0.024440 & 1.000000 \\
\hline & Prauseria & 0.001461 & 0.000534 & 0.029745 & 1.000000 \\
\hline & Arthrobacter & 0.007922 & 0.023226 & 0.033504 & 1.000000 \\
\hline & Lysinibacillus & 0.001449 & 0.003483 & 0.035794 & 1.000000 \\
\hline & Serratia & 0.000746 & 0.000065 & 0.049149 & 1.000000 \\
\hline \multirow[t]{8}{*}{ The tasseling stage } & Myceligenerans & 0.000000 & 0.000211 & 0.000000 & 0.000000 \\
\hline & Actinotalea & 0.000770 & 0.002799 & 0.000704 & 0.283353 \\
\hline & Promicromonospora & 0.002782 & 0.007655 & 0.005394 & 1.000000 \\
\hline & Xylanimicrobium & 0.003661 & 0.010449 & 0.006099 & 1.000000 \\
\hline & Cellulosimicrobium & 0.003349 & 0.009939 & 0.021704 & 1.000000 \\
\hline & Prauseria & 0.001270 & 0.003439 & 0.023070 & 1.000000 \\
\hline & Achromobacter & 0.000058 & 0.000579 & 0.040352 & 1.000000 \\
\hline & Rubellimicrobium & 0.000149 & 0.000040 & 0.041718 & 1.000000 \\
\hline \multirow[t]{24}{*}{ The maturity stage } & Pedomicrobium & 0.000000 & 0.000193 & 0.000000 & 0.000000 \\
\hline & Azotobacter & 0.001508 & 0.006670 & 0.001331 & 0.396812 \\
\hline & Candidatus.Nitrososphaera & 0.003643 & 0.015469 & 0.002013 & 0.400102 \\
\hline & Gemmata & 0.000855 & 0.003225 & 0.003483 & 0.519211 \\
\hline & Agromyces & 0.004015 & 0.007953 & 0.005510 & 0.615288 \\
\hline & Ardenscatena & 0.000420 & 0.003293 & 0.006192 & 0.615288 \\
\hline & Microlunatus & 0.000502 & 0.001481 & 0.007735 & 0.650429 \\
\hline & Flavobacterium & 0.000195 & 0.000706 & 0.009735 & 0.650429 \\
\hline & Rhodoplanes & 0.001726 & 0.004951 & 0.010417 & 0.650429 \\
\hline & Phenylobacterium & 0.000884 & 0.002108 & 0.011715 & 0.650429 \\
\hline & Nitrosovibrio & 0.000023 & 0.000325 & 0.012397 & 0.650429 \\
\hline & Rubricoccus & 0.000325 & 0.001269 & 0.014166 & 0.650429 \\
\hline & Devosia & 0.013335 & 0.046097 & 0.014351 & 0.650429 \\
\hline & Balneimonas & 0.000500 & 0.001813 & 0.015470 & 0.650429 \\
\hline & Fimbriimonas & 0.000324 & 0.001556 & 0.016364 & 0.650429 \\
\hline & Afifella & 0.000386 & 0.001473 & 0.018331 & 0.683069 \\
\hline & Planctomyces & 0.005577 & 0.022402 & 0.019662 & 0.689572 \\
\hline & Sinorhizobium & 0.001518 & 0.003336 & 0.024530 & 0.812488 \\
\hline & lamia & 0.004303 & 0.008824 & 0.029490 & 0.925374 \\
\hline & Virgisporangium & 0.000152 & 0.000585 & 0.033536 & 0.990854 \\
\hline & Pontibacter & 0.000584 & 0.001670 & 0.034901 & 0.990854 \\
\hline & Acinetobacter & 0.000214 & 0.002363 & 0.036914 & 1.000000 \\
\hline & Kaistobacter & 0.004283 & 0.016298 & 0.044212 & 1.000000 \\
\hline & Lysobacter & 0.004849 & 0.007459 & 0.047523 & 1.000000 \\
\hline
\end{tabular}

The quantity is relatively abundance, red indicates that the genus quantity is higher in that group the amount of phytopathogenic bacteria and increase the relative abundance of beneficial bacteria, especially the nitrogen-fixing bacteria and nitrifying bacteria (Table 2). These results added the third possible mechanism of PGPR: regulating the microbiota in rhizosphere and in turn promoting the growth of plants, in addition to the two aspects mentioned above (Numan et al. 2018). The variations in the rhizosphere microbiota of maize in respect to the consortium inoculation and the four growth stages (Table 2, Fig. 2) demonstrated that the rhizosphere microbiota was affected by the interactions between the inoculated consortium and the plant biophysical status. This estimation was also supported by the results of PLS-DA (Fig. 3), in which a clear separation in the rhizosphere microbiota of maize in different growth stages and treatments was observed. For instance, some of the microbiotas from samples of different treatments (with/without inoculation) and different growth stages showed close relationships, while those from the original soils and from the inoculation treatment in the maturity stage formed two groups with great difference. These findings were consistent with the previous observations on the plant associated bacteria that their community composition was determined by the interactions among soil properties, the plant species and the microbes (Román-Ponce et al. 2016; Zhang et al. 2011).

In the present study, genus Exiguobacterium was only detected in control at the three-leaf stage. As salttolerance bacteria, Exiguobacterium usually presented in saline environments (Patel et al. 2018; Remonsellez et al. 2018; Zhang et al. 2019). Cupriavidus was only found in control and Saccharopolyspora was only detected in the consortium inoculated samples in the jointing stage. Cupriavidus usually exists in environments loaded with metal ion, and the bacteria in this genus have been screened from metal ion environments for bioremediation of metal contamination (Huang et al. 2019; von Rozycki and Nies 2009). Therefore, both Exiguobacterium and Cupriavidus might be selected by maize for salt resistance in different growth stages, when the consortium inoculant was absent. The genus Saccharopolyspora contains potential producers of diverse natural products, including antibiotics (Sayed et al. 2020) and insecticide with an excellent environmental and mammalian profile (Tao et al. 2019). So, its augmentation by the consortium inoculation might be beneficial to maize for improving insect resistance, which may be the reason why the inoculation treatment showed fewer pests and diseases (data not shown). At the maturity stage, the presence of more significantly enriched genera in P8/P10/X52 inoculated treatment (Table 2) might be related its greater biomass accumulation (Fig. 1), which made the plant produce more root exudates to support greater abundant 
and diverse rhizosphere microbes. For example, more root exudates (sugars, organic acids, amino acids etc.) can offer greater carbon source to the biological Nfixation and more ammonia to stimulate nitrification, which could be explain why the abundances of Azotobacter, Sinorhizobium, Devosia (N-fixers) and Candidatus Nitrososphaera, Nitrosovibrio (nitrification bacteria) were increased in the inoculation treatment. Azotobacter is usually applied for nitrogen fixation (Kennedy and Toukdarian 1987), but also tolerant to abiotic stresses such as temperature, $\mathrm{pH}$, and insecticides (Chennappa et al. 2016). Root inoculation with Azotobacter chroococcum $76 \mathrm{~A}$ could promote tomato plant growth, stress tolerance, and nutrient assimilation efficiency under moderate and severe salinity (Van Oosten et al. 2018). So, the change in rhizosphere microbiota by the consortium promoted the accumulation of beneficial bacteria in the rhizosphere of maize in saline soil. Therefore, the consortium composed of Pseudomonas sp. P8, Peribacillus sp. P10, and Streptomyces sp. X52 is a promising inoculant, which has the potential to improve crop growth in saline soil. Meanwhile, such consortium as an inoculant may have a more stable and effective impact than inoculants contained only one strain/species of microorganism, and it could be the future development direction of microbial inoculants.

Although Pseudomonas sp. P8, Peribacillus sp. P10, and Streptomyces sp. X52 have beneficial effects in maize growth and altered composition of rhizosphere bacterial community, the results of high-throughput sequencing show that their number or abundance in the rhizosphere of inoculated maize was not high. Therefore, they are likely to affect the growth of maize by stimulating and regulating certain genes of plants, as reported in other studies (Pieterse et al. 2012; Yang et al. 2009), and mediating the rhizosphere microbiota (Table 2, Fig. 2) to affect the growth of maize. PGPRs initially recognized as agents to enhance defense capacity of above ground parts, which was described as induced systemic resistance (ISR) with different pathways (Kawaharada et al. 2015; Pieterse et al. 2012; Zamioudis and Pieterse 2012). In the future, we will study such regulation mechanism, so as to find more efficient PGPR inoculants.

\section{Conclusion}

P8/P10/X52 consortium can promote the growth of maize and promote the accumulation of beneficial bacteria in the rhizosphere of maize in saline soil, which revealed the possibility to use bacterial consortia as inoculants to enhance the crop production in saline soils.

\section{Abbreviations}

PGPR: Plant growth-promoting rhizobacteria; PGP: Plant growth-promoting: EC: Electrical conductivity; ESP: Exchangeable sodium percent; $\mathrm{pH}$ : Potential of hydrogen; mm: Millimeter; ha: Hectare; min: Minute; rpm: Revolutions per minute; mL: Milliliter; KMB: King'B medium; IAA: Indole-3-acetic acid; ACCD: 1 aminocyclopropane-1-carboxylic acid deaminase; CFU: Colony forming unit; rDNA: Ribosomal deoxyribonucleic acid; rRNA: Ribosomal ribonucleic acid;

QIIME: Quantitative insights into microbial ecology; NCBI: National Center for Biotechnology Information; SRA: Sequence read archive; OTUs: Operational taxonomic units; PLS-DA: Partial least squares discriminant analysis;

BLAST: Basic local alignment search tool; IR: Inhibition rates

\section{Supplementary Information}

The online version contains supplementary material available at https://doi. org/10.1186/s13213-021-01650-8.

Additional file 1: Figure S1. The Length Distribution of sequences. Figure S2. The OTU Shannon rarefaction curve. Figure S3. The OTU chao1 rarefaction curve. Figure S4. The OTU observed species rarefaction curve. Supplementary Table S1. Details for antagonistic ability of consortium strains to phytopathogenic fungi. Supplementary

Table S2. The Alpha diversity index of rhizosphere bacteria in the treatments.

\section{Acknowledgements}

This research was done as part of the Talents construction project of science and technology innovation and the Doctoral Program, Hebei Academy of Agriculture and Forestry Sciences.

\section{Authors' contributions}

Dong Hu, Zhanwu Wang, and Jieli Peng designed research and experiments. Jieli Peng wrote the main manuscript text. Jia Ma prepared part of Table 1 and Suppl. Table S1. Xiaoyan Wei prepared Fig. 1 and part of Table 1. Cuimian Zhang, Nan Jia, and Xu Wang performed the plant pot experiment. En Tao Wang provided critical reading and revising suggestion. All authors read, reviewed, and approved the manuscript.

\section{Funding}

This work was supported by funds from the Science \&Technology Program of Hebei (19222902D) and the Project of Natural Science Foundation of Hebei Province (C2020301047). ETW was partially supported by the sabbatical project and SIP20200726 authorized by National Institute of Polytechnology of Mexico.

Availability of data and materials

The raw data have been deposited in SRA database under the accession numbers PRJNA562815.

\section{Declarations}

Ethics approval and consent to participate No applicable.

Consent for publication

All the authors have approved the manuscript that is enclosed.

Competing interests

The authors declare that they have no competing interests.

\section{Author details}

${ }^{1}$ Institute of Agro-resources and Environment (Hebei Fertilizer Technology Innovation Center), Hebei Academy of Agriculture and Forestry Sciences, Shijiazhuang, Hebei, People's Republic of China. ${ }^{2}$ Departamento de Microbiología, Escuela Nacional de Ciencias Biológicas, Instituto Politécnico Nacional, C.P. 11340, Ciudad de México, México.

Received: 17 June 2021 Accepted: 1 September 2021 Published online: 29 September 2021

\section{References}

Akbari A, Gharanjik S, Koobaz P, Sadeghi A (2020) Plant growth promoting Streptomyces strains are selectively interacting with the wheat cultivars 
especially in saline conditions. Heliyon 6:e03445. https://doi.org/10.1016/j. heliyon.2020.e03445

Andreou LV (2013) Preparation of genomic DNA from bacteria. Methods Enzymol 529:143-151. https://doi.org/10.1016/B978-0-12-418687-3.00011-2

Bokulich NA, Subramanian S, Faith JJ, Gevers D, Gordon Jl, Knight R, Mills DA, Caporaso JG (2013) Quality-filtering vastly improves diversity estimates from Illumina amplicon sequencing. Nature methods 10:57-59. https://doi.org/10.1 038/nmeth.2276

Bric JM, Bostock RM, Silverstone SE (1991) Rapid in situ assay for indoleacetic Acid production by bacteria immobilized on a nitrocellulose membrane. Appl Environ Microbiol 57(2):535-538. https://doi.org/10.1128/aem.57.2.535538.1991

Chatterjee P, Samaddar S, Anandham R, Kang Y, Kim K, Selvakumar G, Sa T (2017) Beneficial Soil Bacterium Pseudomonas frederiksbergensis OS261 Augments Salt Tolerance and Promotes Red Pepper Plant Growth. Front Plant Sci 8:705. https://doi.org/10.3389/fpls.2017.00705

Chen L, Liu Y, Wu G, Veronican Njeri K, Shen Q, Zhang N, Zhang R (2016) Induced maize salt tolerance by rhizosphere inoculation of Bacillus amyloliquefaciens SQR9. Physiologia Plantarum 158(1):34-44. https://doi. org/10.1111/ppl.12441

Chen Y, Yang F, Lu H, Wang B, Chen Y, Lei D, Wang Y, Zhu B, Li L (2011) Characterization of fecal microbial communities in patients with liver cirrhosis. Hepatology (Baltimore, Md) 54:562-572. https://doi.org/10.1002/hep.24423

Chennappa G, Naik MK, Adkar-Purushothama CR, Amaresh YS, Sreenivasa MY (2016) PGP potential, abiotic stress tolerance and antifungal activity of Azotobacter strains isolated from paddy soils. Indian J Exp Biol 54:322-331

Chu H, Gao GF, Ma Y, Fan K, Delgado-Baquerizo M (2020) Soil microbial biogeography in a changing world: recent advances and future perspectives. mSystems:5. https://doi.org/10.1128/mSystems.00803-19

Dobereiner J, Marriel IE, Nery M (1976) Ecological distribution of Spirillum lipoferum Beijerinck. Can J Microbiol 22(10):1464-1473. https://doi.org/10.113 9/m76-217

Edgar RC (2010) Search and clustering orders of magnitude faster than BLAST. Bioinformatics (Oxford, England) 26:2460-2461. https://doi.org/10.1093/ bioinformatics/btq461

Egamberdieva D, Jabborova D, Hashem A (2015) Pseudomonas induces salinity tolerance in cotton (Gossypium hirsutum) and resistance to Fusarium root rot through the modulation of indole-3-acetic acid. Saudi J Biol Sci 22:773779. https://doi.org/10.1016/j.sjbs.2015.04.019

Egamberdieva D, Wirth S, Bellingrath-Kimura SD, Mishra J, Arora NK (2019) Salttolerant plant growth promoting rhizobacteria for enhancing crop productivity of saline soils. Front Microbiol 10:2791. https://doi.org/10.3389/ fmicb.2019.02791

Etesami H, Maheshwari DK (2018) Use of plant growth promoting rhizobacteria (PGPRs) with multiple plant growth promoting traits in stress agriculture: action mechanisms and future prospects. Ecotoxicol Environ Saf 156:225-246. https://doi.org/10.1016/j.ecoenv.2018.03.013

Fagundes AA, Silva TC, Voci SM, Dos Santos F, Barbosa KBF, Corrêa AMS (2020) Food and nutritional security of semi-arid farm families benefiting from rainwater collection equipment in Brazil. PloS one 15:e0234974. https://doi. org/10.1371/journal.pone.0234974

Fernandez-Garayzabal JF, Delgado C, Blanco M, Vazquez-Boland JA, Briones V, Suarez G, Dominguez $L$ (1992) Role of potassium tellurite and brain heart infusion in expression of the hemolytic phenotype of Listeria spp. on agar plates. Appl Environ Microbiol 58(1):434-438. https://doi.org/10.1128/aem. 58.1.434-438.1992

Fita A, Rodriguez-Burruezo A, Boscaiu M, Prohens J, Vicente O (2015) Breeding and domesticating crops adapted to drought and salinity: a new paradigm for increasing food production. Front Plant Sci 6:978. https://doi.org/10.3389/ fpls.2015.00978

Frank JA, Reich Cl, Sharma S, Weisbaum JS, Olsen GJ (2008) Critical evaluation of two primers commonly used for amplification of bacterial 165 rRNA Genes. Appl Environ Microbiol 74:2461-2470

Gevers D, Cohan FM, Lawrence JG, Spratt BG, Coenye T, Feil EJ, Stackebrandt E, de Peer W, Vandamme P, Thompson FL, Swings J (2005) Opinion: reevaluating prokaryotic species. Nat Rev Microbiol 3:733-739. https://doi.org/1 $0.1038 /$ nrmicro1236

Hu D, Li S, Li Y, Peng J, Wei X, Ma J, Zhang C, Jia N, Wang E, Wang Z (2020) Streptomyces sp. strain TOR3209: a rhizosphere bacterium promoting growth of tomato by affecting the rhizosphere microbial community. Sci Rep 10: 20132. https://doi.org/10.1038/s41598-020-76887-5
Huang N, Mao J, Hu M, Wang X, Huo M (2019) Responses to copper stress in the metal-resistant bacterium Cupriavidus gilardii CR3: a whole-transcriptome analysis. J Basic Microbiol 59(5):446-457. https://doi.org/10.1002/jobm.201 800693

Ilangumaran G, Smith DL (2017) Plant growth promoting rhizobacteria in amelioration of salinity stress: a systems biology perspective. Front Plant Sci 8:1768. https://doi.org/10.3389/fpls.2017.01768

Kawaharada Y, Kelly S, Nielsen MW, Hjuler CT, Gysel K, Muszyński A, Carlson RW, Thygesen MB, Sandal N, Asmussen MH, Vinther M, Andersen SU, Krusell L, Thirup S, Jensen KJ, Ronson CW, Blaise M, Radutoiu S, Stougaard J (2015) Receptor-mediated exopolysaccharide perception controls bacterial infection. Nature 523:308. https://doi.org/10.1038/nature14611

Kennedy C, Toukdarian A (1987) Genetics of azotobacters: applications to nitrogen fixation and related aspects of metabolism. Annu Rev Microbiol 41(1):227-258. https://doi.org/10.1146/annurev.mi.41.100187.001303

Khalid A, Arshad M, Zahir ZA (2004) Screening plant growth-promoting rhizobacteria for improving growth and yield of wheat. J Appl Microbiol 96(3):473-480. https://doi.org/10.1046/j.1365-2672.2003.02161.x

Li J, Pu L, Han M, Zhu M, Zhang R, Xiang Y (2014) Soil salinization research in China: advances and prospects. J Geogr Sci 24(5):943-960. https://doi.org/1 0.1007/s11442-014-1130-2

Li SP, Wang P, Chen Y, Wilson MC, Yang X, Ma C, Lu J, Chen XY, Wu J, Shu WS, Jiang $L$ (2020) Island biogeography of soil bacteria and fungi: similar patterns, but different mechanisms. ISME J 14:1886-1896. https://doi.org/10.1 038/s41396-020-0657-8

Magoč T, Salzberg SL (2011) FLASH: fast length adjustment of short reads to improve genome assemblies. Bioinformatics 27(21):2957-2963. https://doi. org/10.1093/bioinformatics/btr507

Numan M, Bashir S, Khan Y, Mumtaz R, Shinwari ZK, Khan AL, Khan A, al-Harrasi A (2018) Plant growth promoting bacteria as an alternative strategy for salt tolerance in plants: a review. Microbiol Res 209:21-32. https://doi.org/10.101 6/j.micres.2018.02.003

Nuss ET, Tanumihardjo SA (2010) Maize: a paramount staple crop in the context of global nutrition. Compr Rev Food Sci Food Saf 9(4):417-436. https://doi. org/10.1111/j.1541-4337.2010.00117.x

Olanrewaju OS, Babalola OO (2019) Bacterial Consortium for Improved Maize (Zea mays L.) Production. Microorganisms:7. https://doi.org/10.3390/ microorganisms7110519

Ondrasek G, Rengel Z (2021) Environmental salinization processes: detection, implications \& solutions. Sci Total Environ 754:142432. https://doi.org/10.101 6/j.scitotenv.2020.142432

Paik S, Le D, Nhu L, Mills B (2020) Salt-tolerant rice variety adoption in the Mekong River Delta: Farmer adaptation to sea-level rise. PloS one 15: e0229464. https://doi.org/10.1371/journal.pone.0229464

Palaniyandi SA, Damodharan K, Yang SH, Suh JW (2014) Streptomyces sp. strain PGPA39 alleviates salt stress and promotes growth of 'Micro Tom' tomato plants. J Appl Microbiol 117:766-773. https://doi.org/10.1111/jam.12563

Patel S, Gupta RS (2020) A phylogenomic and comparative genomic framework for resolving the polyphyly of the genus Bacillus: Proposal for six new genera of Bacillus species, Peribacillus gen. nov., Cytobacillus gen. nov., Mesobacillus gen. nov., Neobacillus gen. nov., Metabacillus gen. nov. and Alkalihalobacillus gen. nov. Int J Syst Evol Microbiol 70:406-438. https://doi.org/10.1099/ijsem.0.003775

Patel VK, Srivastava R, Sharma A, Srivastava AK, Singh S, Srivastava AK, Kashyap PL, Chakdar H, Pandiyan K, Kalra A, Saxena AK (2018) Halotolerant Exiguobacterium profundum PHM11 Tolerate Salinity by Accumulating L-Proline and Fine-Tuning Gene Expression Profiles of Related Metabolic Pathways. Front Microbiol 9:423. https://doi.org/10.33 89/fmicb.2018.00423

Penrose DM, Glick BR (2003) Methods for isolating and characterizing ACC deaminase-containing plant growth-promoting rhizobacteria. Physiologia Plantarum 118(1):10-15. https://doi.org/10.1034/j.1399-3054.2003.00086.x

Pieterse CMJ, DVd D, Zamioudis C, Leon-Reyes A, SCMV W (2012) Hormonal modulation of plant immunity. Annu Rev Cel Dev Biol 28(1):489-521. https:// doi.org/10.1146/annurev-cellbio-092910-154055

Remonsellez F, Castro-Severyn J, Pardo-Esté C, Aguilar P, Fortt J, Salinas C, Barahona S, León J, Fuentes B, Areche C, Hernández KL, Aguayo D, Saavedra CP (2018) Characterization and salt response in recurrent halotolerant exiguobacterium sp. SH31 isolated from sediments of Salar de Huasco, Chilean Altiplano. Front Microbiol 9:2228. https:/doi.org/10.3389/fmicb.2018.02228

Román-Ponce B, Ramos-Garza J, Vásquez-Murrieta MS, Rivera-Orduña FN, Chen WF, Yan J, Estrada-de los Santos P, Wang ET (2016) Cultivable endophytic 
bacteria from heavy metal(loid)-tolerant plants. Arch Microbiol 198(10):941956. https://doi.org/10.1007/s00203-016-1252-2

Sayed AM, Abdel-Wahab NM, Hassan HM, Abdelmohsen UR (2020) Saccharopolyspora: an underexplored source for bioactive natural products. J Appl Microbiol 128(2):314-329. https://doi.org/10.1111/jam.14360

Schwyn B, Neilands JB (1987) Universal chemical assay for the detection and determination of siderophores. Anal Biochem 160(1):47-56. https://doi.org/1 0.1016/0003-2697(87)90612-9

Singh A (2021) Soil salinization management for sustainable development: a review. J Environ Manag 277:111383. https://doi.org/10.1016/j.jenvman.202 0.111383

Tao H, Zhang Y, Deng Z, Liu T (2019) Strategies for Enhancing the Yield of the Potent Insecticide Spinosad in Actinomycetes. Biotechnol J 14:e1700769. https://doi.org/10.1002/biot.201700769

Van Oosten MJ et al (2018) Root inoculation with Azotobacter chroococcum 76A enhances tomato plants adaptation to salt stress under low $\mathrm{N}$ conditions. BMC Plant Biol 18:205. https://doi.org/10.1186/s12870-018-1411-5

von Rozycki T, Nies DH (2009) Cupriavidus metallidurans: evolution of a metalresistant bacterium. Antonie Van Leeuwenhoek 96(2):115-139. https://doi. org/10.1007/s10482-008-9284-5

Vyas P, Rahi P, Chauhan A, Gulati A (2007) Phosphate solubilization potential and stress tolerance of Eupenicillium parvum from tea soil. Mycol Res 111(8):931938. https://doi.org/10.1016/j.mycres.2007.06.003

White JR, Nagarajan N, Pop M (2009) Statistical methods for detecting differentially abundant features in clinical metagenomic samples. PLoS Comput Biol 5:e1000352. https://doi.org/10.1371/journal.pcbi.1000352

Wu Z, Yue H, Lu J, Li C (2012) Characterization of rhizobacterial strain Rs-2 with ACC deaminase activity and its performance in promoting cotton growth under salinity stress. World J Microbiol Biotechnol 28:2383-2393. https://doi. org/10.1007/s11274-012-1047-9

Yang J, Kloepper JW, Ryu CM (2009) Rhizosphere bacteria help plants tolerate abiotic stress. Trends Plant Sci 14(1):1-4. https://doi.org/10.1016/j.tplants.2 008.10 .004

Zamioudis C, Pieterse CM (2012) Modulation of host immunity by beneficial microbes. Mol Plant Microbe Interact 25(2):139-150. https://doi.org/10.1094/ mpmi-06-11-0179

Zhang L, Zhang M, Guo J, Zheng J, Chen Z, Zhang H (2019) Effects of K(+) salinity on the sludge activity and the microbial community structure of an A(2)O process. Chemosphere 235:805-813. https://doi.org/10.1016/j. chemosphere.2019.06.137

Zhang YM et al (2011) Biodiversity and biogeography of rhizobia associated with soybean plants grown in the North China. Plain Appl Environ Microbiol 77: 6331-6342

Zhou J, Wu L, Deng Y, Zhi X, Jiang YH, Tu Q, Xie J, van Nostrand JD, He Z, Yang $Y$ (2011) Reproducibility and quantitation of amplicon sequencing-based detection. ISME J 5:1303-1313. https://doi.org/10.1038/ismej.2011.11

\section{Publisher's Note}

Springer Nature remains neutral with regard to jurisdictional claims in published maps and institutional affiliations.

Ready to submit your research? Choose BMC and benefit from:

- fast, convenient online submission

- thorough peer review by experienced researchers in your field

- rapid publication on acceptance

- support for research data, including large and complex data types

- gold Open Access which fosters wider collaboration and increased citations

- maximum visibility for your research: over $100 \mathrm{M}$ website views per year

At BMC, research is always in progress.

Learn more biomedcentral.com/submissions 